\title{
Draft genome sequence of Bacillus thuringiensis 147, a Brazilian strain with high insecticidal activity
}

\author{
Luiz Carlos Bertucci Barbosa ${ }^{1 /+}$, Débora Lopes Farias ${ }^{2}$, Isabella de Moraes Guimarães Silva ${ }^{2}$, \\ Fernando Lucas Melo ${ }^{3}$, Bergmann Morais Ribeiro3 ${ }^{3}$, Raimundo Wagner de Souza Aguiar²
}

\author{
${ }^{1}$ Universidade Federal de Itajubá, Instituto de Recursos Naturais, Itajubá, MG, Brasil \\ ${ }^{2}$ Universidade Federal do Tocantins, Departamento de Engenharia de Bioprocessos e Biotecnologia, Gurupi, TO, Brasil \\ ${ }^{3}$ Universidade de Brasília, Departamento de Biologia Celular, Brasília, DF, Brasil
}

Bacillus thuringiensis is a ubiquitous Gram-positive and sporulating bacterium. Its crystals and secreted toxins are useful tools against larvae of diverse insect orders and, as a consequence, an alternative to recalcitrant chemical insecticides. We report here the draft genome sequence of $\mathrm{B}$. thuringiensis 147, a strain isolated from Brazil and with high insecticidal activity. The assembled genome contained 6,167,994 bp and was distributed in seven replicons (a chromosome and 6 plasmids). We identified 12 coding regions, located in two plasmids, which encode insecticidal proteins.

Key words: Bacillus thuringiensis - biopesticides - genome sequence

Bacillus thuringiensis is a Gram-positive bacterium that has been isolated from a range of ecosystems including soil, water and dead insects, among others. $B$. thuringiensis is a spore-forming bacterium that synthesises parasporal crystalline inclusions containing Cry and Cyt proteins (also known as $\delta$-endotoxins) and some of these are toxic against a wide range of insect orders, nematodes and human cancer cells (Palma et al. 2014). $B$. thuringiensis isolates can also synthesise and secrete other insecticidal proteins during the vegetative growth phase, which are designated vegetative insecticidal proteins (Vip) and secreted insecticidal protein (Sip). Furthermore, other predicted toxins are also produced by $B$. thuringiensis strains, but their toxicity has yet to be proven (Palma et al. 2014).

The crystals and secreted toxins of B. thuringiensis are highly specific for their hosts and have therefore gained worldwide importance as an alternative to chemical insecticides, motivating the search for new $B$. thuringiensis isolates to identify and characterise new insecticidal proteins (Pardo-López et al. 2013, Palma et al. 2014). Accordingly, whole genome sequence of these isolates can be an important starting point. In this study, we determined the draft genome sequence of $B$. thuringiensis 147, a strain isolated from soil samples in the state of Tocantins, Brazil. Toxicity assays of this strain have shown high insecticidal activity against larvae from Aedes aegypti (Diptera: Culicidae) and Spodoptera frugiperda (Lepidoptera: Noctuidae).

doi: $10.1590 / 0074-02760150273$

Financial support: CNPq, SECT-TO

+ Corresponding author: luiz_cbb@hotmail.com

Received 21 July 2015

Accepted 21 August 2015
For genome sequencing, total DNA (chromosome and plasmids) was isolated using the Wizard Genomic DNA Purification kit (Promega) from fresh overnight cultures. Whole-genome sequencing was performed with the MiSeq platform (Illumina, USA), located at the High-Performance Genome Centre of Federal District (Brasília, Brazil) using the 600-cycle MiSeq reagent kit v.3 (Illumina). A total of 2,614,978 paired-end reads were generated at a read length of $150 \mathrm{bp}$. A quality control of these reads was performed with the FastQC tool (bioinformatics.babraham.ac.uk/projects/fastqc/). De novo genome assembly was carried out with SPAdes 3.5.0 (Bankevich et al. 2012). The final draft genome assembly consisted of 94 contigs (length $>=500 \mathrm{bp}$ ), with a total size of $6,167,994 \mathrm{bp}, \mathrm{N} 50$ value of 205,568 and a mean guanine-cytosine content of $34.90 \%$. A BLAST analysis (blast.ncbi.nlm.nih.gov/blast/Blast.cgi) of each contig showed that the assembled genome was distributed in seven replicons: a circular chromosome and six plasmids. The genetic information about these replicons is summarised in Table I.

Automated annotation, carried out using the RAST annotation server (Aziz et al. 2008), showed that the draft genome of $B$. thuringiensis strain 147 contains 6,319 predicted protein-coding sequences and 138 predicted RNAs (rRNAs and tRNAs). These data are consistent with other published complete genomes from $B$. thuringiensis strains (Doggett et al. 2013, Liu et al. 2014, Johnson et al. 2015). In addition to the analysis performed by the RAST annotation server, the identification and annotation of insecticidal genes were performed with BLAST (Altschul et al. 1997), using a custom insecticidal toxin database from $B$. thuringiensis. The local custom database was constructed with amino acid sequences of $\delta$-endotoxins (Cry and Cyt), secreted toxins (Vip and Sip), proteins called "mosquitocidal toxin" and haemagglutinin-related proteins, all retrieved from the curated UniProtKB database (uniprot.org/uniprot/). All insecticidal proteins identified using a local data- 
TABLE I

Genetic information about the replicons from Bacillus thuringiensis 147

\begin{tabular}{lccc}
\hline Replicon & $\begin{array}{c}\text { Length } \\
(\mathrm{bp})\end{array}$ & $\begin{array}{c}\text { GC content } \\
(\%)\end{array}$ & $\begin{array}{c}\text { Predicted genes } \\
(\mathrm{n})\end{array}$ \\
\hline Chromosome & $5,337,997$ & 35.07 & 5,602 \\
Plasmid 1 & 357,957 & 32.32 & 355 \\
Plasmid 2 & 5,053 & 34.93 & 3 \\
Plasmid 3 & 235,436 & 36.59 & 267 \\
Plasmid 4 & 217,152 & 32.99 & 219 \\
Plasmid 5 & 7,640 & 35.33 & 8 \\
Plasmid 6 & 6,759 & 35.61 & 3 \\
\hline
\end{tabular}

GC: guanine-cytosine. base were confirmed using remote BLAST (blast.ncbi. nlm.nih.gov/blast/Blast.cgi). Insecticidal genes were confined to two plasmids. Plasmid 1 and plasmid 4 were found to harbour one and 11 insecticidal genes, respectively. Table II summarises the regions of the assembled contigs that encode insecticidal proteins.

This Whole Genome Shotgun project has been deposited at DDBJ/EMBL/GenBank under the accession LFXM00000000. The version described in this paper is version LFXM01000000.

\section{TABLE II}

Predicted regions that encode insecticidal proteins (or fragments of these)

\begin{tabular}{lccccc}
\hline Replicon & Contig & Start & End & Strand & BLAST description \\
\hline Plasmid 1 & 88 & 21,036 & 22,583 & + & Mosquitocidal toxin protein \\
Plasmid 4 & 10 & 5,906 & 5,115 & - & Type-2Ba cytolytic delta-endotoxin \\
& 20 & 12,527 & 11,616 & - & Cry protein \\
& 45 & 2,814 & 4,841 & + & Pesticidal crystal protein Cry10Aa \\
& 53 & 6,603 & 6,313 & - & Pesticidal crystal protein Cry4Aa \\
& 8 & 5 & 295 & + & Pesticidal crystal protein Cry4Ba \\
& 84 & 115 & 261 & + & Pesticidal crystal protein Cry4Ba \\
& 84 & 2,719 & 1,142 & - & Toxin protein/Cyt-like protein \\
& 9 & 13,868 & 13,119 & - & Pesticidal crystal protein Cryl1Bb \\
& 9 & 15,535 & 17,466 & + & Pesticidal crystal protein Cry28Aa \\
& 9 & 18,651 & 18,776 & + & Haemagglutinin-related protein
\end{tabular}

\section{REFERENCES}

Altschul SF, Madden TL, Schäffer AA, Zhang J, Zhang Z, Miller W, Lipman DJ 1997. Gapped BLAST and PSI-BLAST: a new generation of protein database search programs. Nucleic Acids Res 25: 3389-3402.

Aziz RK, Bartels D, Best AA, DeJongh M, Disz T, Edwards RA, Formsma K, Gerdes S, Glass EM, Kubal M, Meyer F, Olsen GJ, Olson R, Osterman AL, Overbeek RA, McNeil LK, Paarmann D, Paczian T, Parrello B, Pusch GD, Reich C, Stevens R, Vassieva O, Vonstein V, Wilke A, Zagnitko O 2008. The RAST server: rapid annotations using subsystems technology. BMC Genomics 9: 75.

Bankevich A, Nurk S, Antipov D, Gurevich AA, Dvorkin M, Kulikov AS, Lesin VM, Nikolenko SI, Pham S, Prjibelski AD, Pyshkin AV, Sirotkin AV, Vyahhi N, Tesler G, Alekseyev MA, Pevzner PA 2012. SPAdes: a new genome assembly algorithm and its applications to single-cell sequencing. J Comput Biol 19: 455-477.

Doggett NA, Stubben CJ, Chertkov O, Bruce DC, Detter JC, Johnson SL, Han CS 2013. Complete genome sequence of Bacillus thuringiensis serovar israelensis strain HD-789. Genome Announc 1: e01023-13.

Johnson SL, Daligault HE, Davenport KW, Jaissle J, Frey KG, Ladner JT, Broomall SM, Bishop-Lilly KA, Bruce DC, Gibbons HS, Coyne SR, Lo CC, Meincke L, Munk AC, Koroleva GI, Rosenzweig CN, Palacios GF, Redden CL, Minogue TD, Chain PS 2015. Complete genome sequences for 35 biothreat assay-relevant bacillus species. Genome Announc 3: e00151-15.

Liu X, Zhou R, Fu G, Zhang W, Min Y, Tian Y, Huang D, Wang K, Wan Z, Yao J, Yang Z 2014. Draft genome sequence of Bacillus thuringiensis NBIN-866 with high nematocidal activity. Genome Announc 2: e00429-14.

Palma L, Muñoz D, Berry C, Murillo J, Caballero P 2014. Bacillus thuringiensis toxins: an overview of their biocidal activity. Toxins 6: 3296-3325.

Pardo-López L, Soberón M, Bravo A 2013. Bacillus thuringiensis insecticidal three-domain Cry toxins: mode of action, insect resistance and consequences for crop protection. FEMS Microbiol Rev 37: 3-22. 